\title{
COMUNIDADES NEGRAS RURAIS E COMUNIDADES REMANESCENTES DE QUILOMBO: CATEGORIAS, IDENTIDADES E DIREITOS EM DISCUSS ÃO ${ }^{1}$
}

\author{
Rita de Cássia Domingues Lopes ${ }^{2}$
}

\begin{abstract}
RESUMO
O texto trata da reflexão sobre as categorias: comunidade negra rural e comunidade remanescente de quilombo numa perspectiva de identidades e direitos, trazendo como estudo de caso uma comunidade remanescente de quilombo no norte do estado do Tocantins - a comunidade quilombola Ilha de São Vicente, caracterizando-se como uma pesquisa bibliográfica e estudo de caso. O artigo terá uma breve contextualização do estado do Tocantins e em seguida a discussão das categorias mencionadas. Como resultado é possível afirmar que grupos sociais assumem suas identidades para atender as questões jurídicas, políticas, sociais e culturais, e as comunidades negras rurais descendentes dos antigos quilombos ou dos antigos grupos de camponeses negros (SCHMITT; TURATTI; CARVALHO, 2002), têm uma profunda relação com o território, que deve ser efetivado na prática porque já está garantido pela legislação.
\end{abstract}

Palavras-chave: Comunidade negra rural. Comunidade remanescente de quilombo. Estado do Tocantins.

\begin{abstract}
The text deals with the reflection on the categories: rural black community and remnant quilombo community in a perspective of identities and rights, bringing as a case study a remnant quilombo community in the north of the state of Tocantins - the quilombola community Ilha de São Vicente, featuring itself as a literature search and case study. The article will briefly contextualize the state of Tocantins and then discuss the categories mentioned. As a result, it is possible to affirm that social groups assume their identities to meet legal, political, social and cultural issues, and the rural black communities descended from the old quilombos or the old groups of black peasants (SCHMITT; TURATTI; CARVALHO, 2002), have a deep relationship with the territory, which must be carried out in practice because it is already guaranteed by legislation.
\end{abstract}

Keywords: Rural black community. Remaining quilombo community. State of Tocantins.

Data de submissão: 25.10 .2020 Data de aprovação: 09. 11. 2020

\section{INTRODUÇÃO}

O trabalho é uma reflexão sobre as categorias: comunidade negra rural e comunidade remanescente de quilombo numa perspectiva de identidades e direitos, para pensar nas comunidades remanescentes de quilombo no norte do estado do Tocantins (LOPES, 2019). Será uma discussão teórica com apresentação de um estudo de caso sobre uma comunidade quilombola localizada na região do Bico do Papagaio - Tocantins.

O texto consistirá além da introdução, de um subitem tratando brevemente do estado do Tocantins; e outro subitem apresentando e discutindo as categorias acima mencionadas, que são o mote deste trabalho e, por fim, a conclusão.

\footnotetext{
${ }^{1}$ Artigo originalmente apresentado no III Simpósio Internacional sobre Estado, Sociedade e Políticas Públicas (III SINESPP), evento organizado pelo Programa de Pós-Graduação em Políticas Públicas da UFPI, realizado em outubro de 2020.

${ }^{2}$ Doutora em Antropologia. Professora Adjunta na Universidade Federal do Tocantins (UFT). Campus de Tocantinópolis. E-mail: ritadomingueslopes@gmail.com
} 


\section{BREVE CONTEXTUALIZAÇÃO SOBRE O ESTADO DO TOCANTINS}

O estado do Tocantins é o mais novo estado da Federação com 31 anos, foi criado com a promulgação da Constituição Federal de 1988, sendo desmembrado do Estado de Goiás e implantado em 01 de janeiro de 1989, fazendo parte da Região Norte, tendo como sua capital a cidade de Palmas. O estado tem uma área territorial de $277.620,914 \mathrm{~km}^{2}$, faz limites com seis Estados brasileiros, são eles: Pará, Maranhão, Piauí, Bahia, Goiás e Mato Grosso. (NASCIMENTO, 2009). Possui 139 municípios com uma população estimada pelo IBGE para 2019 em 1.572.866 habitantes. A capital Palmas, com 299.127 habitantes. As duas maiores cidades depois da capital são: Araguaína, ao norte, com 180.470 habitantes e Gurupi, ao sul, com 86.647 habitantes (BRASIL. IBGE, 2020).

No setor econômico o estado do Tocantins historicamente era conhecido pela agropecuária e a mineração, na época que fazia parte do estado de Goiás. Hoje a atividade agropecuária ainda continua, com a pecuária de corte da raça Nelore (NASCIMENTO, 2009). $\mathrm{O}$ agronegócio se fixou no estado "[...] onde máquinas e técnicas aplicadas às pastagens e à engorda [do gado] alcançam uma alta produtividade" (NASCIMENTO, 2009, p. 94), o agronegócio é entendido como "[...] a soma dos setores produtivos com os de processamento do produto final e os de fabricação de insumos [...]" (GUANZIROLI, 2006, p. 03), que compreende agricultura, aquicultura, pecuária, agroenergia e irrigação para produção de frutas.

Na agricultura tem-se o plantio de soja, mas há outras plantações como de arroz e milho. Têm-se, ainda, as plantações de eucalipto e seringueira, e registra-se a piscicultura, a avicultura, a suinocultura, a apicultura, a produção de biodiesel (etanol), a plantação de mandioca e a fruticultura no Estado (NASCIMENTO, 2009).

As transformações do agronegócio nos últimos anos ocorridos no Brasil atingiram também o Tocantins e que "alterou completamente a geopolítica do campo" (NASCIMENTO, 2009 , p. 94). Grandes áreas de terras foram reservadas para o remanejamento dos segmentos do agronegócio como a soja e o eucalipto, enquanto os grupos sociais minoritários ficaram com o lado pobre e seco da terra considerada improdutiva, sofrendo com grandes restrições em sua forma de trabalhar. Mesmo havendo por parte do Estado a implantação de projetos agrícolas para plantação de outras culturas, principalmente, frutas, constata-se que não atingiu todos os pequenos agricultores.

Não podemos deixar de referir que desde 2015 todo o estado do Tocantins faz parte do plano de desenvolvimento agropecuário empregado na região central do Brasil denominado de MATOPIBA, um acrônimo das siglas dos quatro estados que fazem parte deste plano: Maranhão (MA), Tocantins (TO), Piauí (PI) e Bahia (BA). Esse território abrange três biomas, 90,9\% Cerrado, 7,2\% Amazônia e 1,64\% Caatinga, a maior parte fica no bioma cerrado (MIRANDA, 2015; BUAINAIN; GARCIA; VIEIRA FILHO, 2018).

Como dito anteriormente, o estado de Tocantins faz parte geopoliticamente da região norte, e em termos ambientais encontra-se na zona de transição geográfica entre o cerrado e a Floresta Amazônica, constatado na fauna e flora locais, onde é possível identificar animais e plantas das duas regiões.

No Tocantins atualmente são 45 comunidades quilombolas certificadas pela Fundação Cultural Palmares. Além dessas, há outras comunidades que não foram certificadas pela Fundação Palmares no estado. Conforme os dados da Organização Não-Governamental Estadual, chamada Alternativas para Pequena Agricultura no Tocantins (APA-TO) há conhecimento de 09 comunidades que não possuem certificação e nem estão com processo formalizado no Instituto Nacional de Colonização e Reforma Agrária (APA-TO, 2012), mas estimasse aproximadamente 20 comunidades que se autointitulam quilombolas sem certificação da Fundação Palmares (LOPES, 2019).

As regiões sul e sudeste do Tocantins são as regiões que se concentram o maior número de comunidades quilombolas, isso se deve ao fato de que nesta parte do antigo norte 
goiano era área de mineração, para onde foram levados muitos escravos para o trabalho nas minas. No norte do estado do Tocantins há 10 comunidades quilombolas a Comunidade citada neste trabalho será a Ilha de São Vicente onde seus ancestrais foram levados escravizados do Nordeste (Maranhão) para o antigo norte de Goiás.

\section{COMUNIDADE NEGRA RURAL, COMUNIDADE REMANESCENTE DE QUILOMBO: CATEGORIAS, IDENTIDADES E DIREITOS EM DISCUSSÃO}

A reflexão será sobre as categorias: comunidade negra rural, comunidade remanescente de quilombo e outras denominações referentes à população negra que vive em áreas rurais e urbanas, em uma perspectiva de analisar as identidades construídas com o passar das décadas, a adequação ao momento histórico vivido e a construção teóricaacadêmica sobre os atores e sujeitos de suas histórias que são pesquisados.

$\mathrm{Na}$ discussão sobre as comunidades quilombolas há necessidade de recuar e recorrer à história para entender a autoidentificação das comunidades negras rurais como remanescente de quilombo, não há pretensão de se fazer um estudo histórico detalhado sobre o assunto, mas trazer alguns elementos que trarão luzes para pensar no contexto atual.

Neste sentido, recuaremos a 1740, quando o então rei de Portugal, D. João V, respondeu à consulta feita pelo Conselho Ultramarino, que definiu quilombo como sendo: "toda habitação de negros fugidos que passem de cinco, em parte despovoada, ainda que não tenham ranchos levantados nem se achem pilões nele."” (MOURA, 1981, p. 16).

Partindo dessa definição de 1740, feita durante o período do Brasil colônia e que foi ensinada pelos antigos livros de história do Brasil, permanece até hoje a ideia de que os "quilombos são lugares de escravos fugidos", esta é uma visão. A outra ressemantiza esse conceito e amplia a concepção de quilombo, argumentando que não necessariamente deve ser unicamente associada à fuga de escravos e ao isolamento, mas sim reconhecer a variedade de processos de ocupação do território feita pela população negra no país, de norte a sul. Além disso, os grupos que se veem e são reconhecidos como comunidades quilombolas hoje, não passaram por um único processo de formação tanto durante quanto após a escravidão.

As comunidades quilombolas passam, segundo Alfredo W. Almeida (2011, p. 21), pelo processo de ressemantização do conceito, onde "[...] a relativização nos conduz ao repertório de práticas e às autodefinições dos próprios agentes sociais que vivem e construíram as diversas situações hoje designadas como quilombo", mas para alguns políticos, juristas e outros profissionais, essa ressemantização contraria a "[...] definição jurídico-formal historicamente cristalizada [...] e os marcos jurídicos instituídos no século XVIII [...] do suposto significado 'original'." (Ibid., p. 34) de quilombo, que ainda tende a perdurar até hoje. Para Almeida (Ibid.), "[...] alcançar as novas dimensões do significado atual de quilombo" é preciso colocar em dúvida e considerar arbitrária a "[...] definição jurídica congelada [...] do período colonial." (Ibid., p. 35) e ir além.

Autores como O’Dwyer (2002), Arruti (2008) e Alfredo W. Almeida (2011) dizem que o conceito de quilombo na República foi ressemantizado. Arruti (2008) cita, pelo menos, três elementos que demonstram essa ressignificação: "resistência cultural", "resistência política" e "resistência negra", ampliando para um campo de luta e disputa por direitos.

No final do século XX, o conceito de quilombo foi retomado e reintroduzido na Constituição Federal de 1988, como um elemento de "sobrevivência" do conceito do passado como "remanescente" ou resíduo. Alfredo W. Almeida (2011, p. 43, grifo do autor) diz que: "De categoria de atribuição formal, através da qual se classificava um crime, quilombo passa a ser considerado como categoria de auto-definição [sic], provocada para reparar um dano". No passado admitir ser um quilombola "[...] equivalia ao risco de ser posto à margem da lei e

\footnotetext{
${ }^{3}$ Esse é um conceito histórico-jurídico de quilombo, que remonta ao período colonial e permaneceu durante o período imperial com a política de repressão aos quilombolas.
} 
ao alcance dos instrumentos repressivos. "(ALMEIDA, 2011, p. 43), por isso, ao longo da história dos grupos sociais, os seus territórios tiveram outras nomenclaturas para muitas vezes não serem pegos, e o local onde moravam eram conhecidos como "terra de preto, terra de herança, terras de santo, terras de índio, bem como às doações, concessões e aquisição de terra. Cada grupo tem sua própria história, legitimando sua condição, e construiu sua identidade coletiva a partir dela." (Ibid., p. 43). Portanto, ressalta-se que esta nova categoria criada "remanescente de quilombo" não é uma sobra/resíduo do passado, mas sim, o reconhecimento da multiplicidade de questões identitárias, políticas, econômicas e territoriais que constituíram as comunidades de hoje.

Antes da definição constitucional de 1988, as comunidades negras vistas a partir da ótica do campesinato, que hoje se autoidentificam como quilombolas, foram chamadas em um determinado momento histórico de comunidades negras rurais (ARRUTI, 1998, 2002; O'DWYER, 2002; MAESTRI, 2005b; FIABANI, 2007; LOPES, 2008), nos trabalhos antropológicos e históricos coligidos foram encontradas outras denominações que foram organizadas em um quadro (Quadro 1), no exercício de sistematizar as categorias encontradas nos autores, a partir da década de $1990^{4}$.

Quadro 1 - Outras denominações para comunidades negras rurais

\begin{tabular}{ll}
\hline \multicolumn{1}{c}{ Outras denominações } & \multicolumn{1}{c}{ Autoras e Autores } \\
\hline Comunidades negras autônomas ou comunidades camponesas livres & Karasch, 1996 \\
Comunidades negras rurais quilombolas & Ratts, 2000 e 2009 \\
Grupos rurais negros ou grupos camponeses negros & Schmitt; Turatti; Carvalho, 2002 \\
Comunidades de camponeses negros ou camponeses negros & Maestri, 2005 a/b \\
Comunidades trabalhadoras rurais brasileiras afrodescendentes & Fiabani, 2007 \\
Comunidades rurais afrodescendentes ou comunidades negras agrárias & Fiabani, 2007 e 2012 \\
\hline
\end{tabular}

Fonte: LOPES, 2019, p. 88

Essas denominações nos fazem pensar que não se trata somente de categorizá-las e nominá-las, mas sim entender o processo pelo qual os grupos de negros livres e os exescravizados foram se organizando antes e depois da assinatura da Lei Áurea em todo o Brasil.

Moura (2012) lembra que os primeiros estudos voltados para as comunidades negras rurais estavam ligados às questões de terra, identidade étnica, política e economia, e informa ainda que desde a década de 1970 as pesquisas tinham um enfoque de "estudos de comunidades". Esse assunto não será discutido aqui, mas deixar-se-á claro que, na produção antropológica/sociológica, houve um momento teórico em que se usava a categoria comunidades negras rurais e, hoje, a categoria utilizada é comunidades remanescentes de quilombo, que trata de uma "nova" realidade no contexto de análise das comunidades.

Reesink (2008), discute a questão das categorias que, antes, as comunidades negras rurais eram classificadas como "raciais" e que, com o passar do tempo e as pesquisas acadêmicas, passaram a ser consideradas "grupos étnicos". O autor diz que esta categorização e mudança de abordagem teórica, muitas vezes, não são discutidas e nem detalhadas nas pesquisas. Para ele, isso decorre da interpretação parcial do conceito proposto por Fredrick Barth e também de questões políticas. Para Reesink (2008), deve-se explicar o processo, discutir a passagem de uma categoria a outra (de racial para grupos étnicos) e como isso acontece dentro das comunidades negras rurais, não basta apenas referir Barth, isso não é suficiente para explicar a presença dos grupos étnicos e a mudança conceitual que houve nos estudos sobre as comunidades negras rurais no Brasil nos últimos anos.

A mudança de abordagem nos estudos/pesquisas sobre as populações negras rurais, passando para as questões étnicas, é percebida mais acentuadamente desde 1988, quando foi inserida a nova categoria jurídica "remanescentes de quilombo", por meio da Constituição.

\footnotetext{
${ }^{4}$ Esse quadro é o início de uma sistematização das categorias e, certamente, deve ser completado.
} 
A obra "Agricultura, escravidão e capitalismo" (1979) de Ciro Flamarion S. Cardoso traz uma contribuição para pensar o capitalismo e a escravidão. Nessa obra, dentre os vários argumentos e hipóteses apresentados pelo autor destaca-se o capítulo "A brecha camponesa no sistema escravista", o da existência de um "protocampesinato escravo", isto é, durante o sistema escravista havia uma parcela de terra (pequena) dentro da grande propriedade do senhor destinada às plantações para subsistência dos escravos, cuidada pelos próprios escravos em um dia da semana pré-determinado e específico, e o pouco excedente que tinham podiam negociar, isso não significava "liberdade" aos escravos, mas sim, um "alívio" para os proprietários das fazendas nos gastos para alimentar e vestir os escravos nas fazendas. Outro motivo citado no livro é que assim criava-se vínculo do escravo com a terra, na tentativa de evitar as fugas, o que, porém, nem sempre acontecia. Nem todas as fazendas adotaram tal prática.

Esta característica de plantar e colher os produtos de suas pequenas parcelas de terras, mesmo sendo uma atividade secundária, segundo Cardoso $(1979 ; 2004)$, indica a formação do "escravo-camponês" e de um "protocampesinato" no interior das fazendas e das plantations. E que, em cada região do Brasil, aconteceu de uma forma, de acordo com Cardoso (2004) citando Funes (1983), diz que, em Goiás, a produção camponesa (ou protocamponesa) tinha uma autonomia na produção em relação à fazenda. Citando Mattos (1985), sobre a região nordestina do Seridó, diz que alguns escravos tinham gado obtidos como forma de pagamento de dívidas "[...] pela compra de gêneros alimentícios [...] [demonstrando] a inserção do protocampesinato escravo nos circuitos mercantis locais. "(Apud CARDOSO, 2004, p. 106).

Silva Filho (2012, p. 91) argumenta que “[...] é razoável supor que um protocampesinato de origem mestiça e/ou negra começasse a deitar raízes na região norte da Capitania de Goiás [...] em potencialidade, será berço de toda uma ampla organização de comunidades negras rurais [na região]". Cardoso (2004) utiliza o argumento de Sidney Mintz (1974), na definição do protocampesinato escravo, que diz: "[...] as atividades agrícolas autônomas dos escravos nas parcelas e no tempo para cultivá-las, que lhes eram concedidos dentro das plantations, e a venda de todo excedente eventual de alimentos assim produzidos [...]" (CARDOSO, 2004, p. 114-115), tem sido muito estudado no Caribe e no Sul dos Estados Unidos, mas foi pouco estudado no Brasil, mesmo as comunidades negras que ficaram na terra e trabalharam nela após a escravidão, e mantiveram até hoje uma produção variada de alimentos.

Na economia que existia nos quilombos Clóvis Moura (1981) e Alfredo W. Almeida (2011) citam as roças como um elemento característico de alguns quilombos. Outro elemento importante é o trabalho da unidade familiar, como disse Almeida (2011, p. 62), o "[...] acamponesamento ou a [sic] unidades do trabalho familiar autônomas economicamente em virtude do processo de desagregação das fazendas de algodão e cana de açúcar e com a decorrente diminuição do poder de coerção dos grandes proprietários territoriais". Fora das fazendas, fora da parcela de terra cedida pelos senhores aos escravizados, havia uma produção econômica considerável que vinha dos quilombos.

Segundo Shanin (1990, p. 05), “[...] o camponês deve ser compreendido através da investigação das características do estabelecimento rural familiar camponês, tanto internas quanto externas, isto é, suas especificidades reações e interações com o contexto social mais amplo", tomando esta perspectiva de Shanin, o que os escravos faziam não era propriamente um campesinato porque trabalhavam escravizados, forçados em outras atividades, por isso Cardoso (1979; 2004) chamou de "protocampesinato", o início, anterior ao campesinato desenvolvido hoje.

Para refletir na formação do campesinato brasileiro, deve-se levar em consideração a "via quilombola e a via escravista" (MAESRI, 2005a, p. 251), isto é, a produção advinda das populações negras rurais que estavam livres ou escravizadas. O campesinato brasileiro foi criado, dirá Marques (2008, p. 60), “[...] no seio de uma sociedade situada na periferia do capitalismo e à margem do latifúndio escravista.". Carvalho (1978), faz referência ao que 
caracteriza a sociedade brasileira e a sua estrutura rural até a segunda metade do século XIX, que foi a escravidão: "[...] os escravos se fazem presentes [...] na formação do camponês, agricultor de baixa renda ou de subsistência. " (Op. cit., p. 73). Para Carvalho, a incorporação dos ex-escravizados como camponeses se resume que esta condição lhes dava "liberdade e autonomia em sua força de trabalho" (Op. cit., p. 91) e porque, para alguns grupos, os seus costumes estavam ligados ao ambiente de características rurais.

As comunidades que hoje se autodeclaram como remanescentes de quilombo, antes de $1988^{5}$, não eram chamadas e nem conhecidas por este nome, até mesmo porque era uma categoria inexistente antes desse ano. As comunidades eram conhecidas e chamadas de "comunidades de pretos ou terras de preto" (ALMEIDA, A. W., 2009), ou, ainda "os pretos de determinado lugar", vistos pelo viés do campesinato eram e/ou são chamadas de "comunidades negras rurais" (ARRUTI, 1998, 2002; MAESTRI, 2005b; FIABANI, 2007; JORGE, 2016); ou outras denominações apresentadas anteriormente no quadro 1, todas elas ligadas às características que se referem à população negra, que formam comunidades, que vivem e trabalham no campo/na área rural do país.

As terras ocupadas pelas comunidades remanescentes de quilombo são cobiçadas por fazendeiros, empresários, grileiros entre outros, por isso, a luta pela titulação das terras é constante. O próprio termo "remanescente de quilombos" que foi oficializado na Constituição Brasileira de 1988, no seu Art. 68 do Ato das Disposições Constitucionais Transitórias (ADCT) expressa "Aos remanescentes das comunidades dos quilombos que estejam ocupando suas terras, é reconhecida a propriedade definitiva, devendo o Estado emitir-lhes títulos respectivos" garantindo automaticamente o direito de posse das terras ocupadas e/ou herdadas de seus antepassados. A lei diz isso, mas sua implementação foi e continua sendo lenta, devido há vários interesses econômicos, políticos e sociais envolvidos.

Essa categoria juridicamente nova que é a comunidade remanescente de quilombo reúne vários casos e situações diferenciadas de identificação e identidade de pessoas que não sabiam ou não queriam lembrar do passado sofrido e foram colocados, encaixados dentro deste termo. Para Gusmão "A visão exterior e desconhecimento dos que fazem as leis sobre os que lutam por direitos da realidade negra no meio rural brasileiro, ao tentar corrigir uma injustiça através do dispositivo constitucional, acrescentou a possibilidade de distorção jurídica do próprio direito pretendido e conquistado". A autora chama atenção ainda para a “insuficiência conceitual, prática, histórica e política do termo ‘quilombo' para dar conta da diversidade das formas de acesso à terra e das formas de existir das comunidades negras no campo." (GUSMÃO, 1992, p. 121).

Desde a criação e implementação em 1988 algumas comunidades quilombolas veem trabalhando internamente as questões de identidade e direito entre outras questões, mas foi a partir da implementação de políticas públicas voltadas para a população negra tanto da cidade quanto do campo que esse assunto se solidificou e tornou-se público, sem medo de expressar quem são ou de exigir seus direitos.

Para muitas comunidades negras dispersas pelo país se verem como quilombola foi e está sendo uma perspectiva nova, uma identidade nova revelada, porque muitas pessoas se viam antes como sendo "dali mesmo, [daquele lugar] de uma mesma família" (CHAGAS, 2001, p. 227). Muitas comunidades negras, por fazerem parte daquele lugar há muito tempo, são conhecidas na região onde vivem, estão recuperando a história de suas comunidades e conhecendo melhor a si mesmos.

Foi o que aconteceu com a Comunidade remanescente de quilombo Ilha de São Vicente. $\mathrm{O}$ acionamento dessa identidade foi a partir do conflito gerado pela disputa de terra que levou ao despejo e a mobilização da comunidade pelo retorno à sua terra e fez vir à tona a história e identidade quilombola, levando aos idosos uma palavra nova que antes

\footnotetext{
${ }^{5}$ Para maiores detalhes sobre a configuração da "questão quilombola" e os discursos da Antropologia, do Estado brasileiro (Executivo e Judiciário) sobre os quilombos e quilombolas, consultar Jorge (2016).
} 
desconheciam. O novo contexto jurídico acionou um elemento oculto em suas histórias, mas as histórias estavam lá, nas memórias e lembranças dos mais velhos da comunidade.

A Comunidade quilombola Ilha de São Vicente sofreu com as mudanças em seu meio de vida, porque, depois de iniciado o conflito pela terra, onde suas terras foram violentamente tomadas, situação que envolveu despejo, destruição e queimada de suas casas, plantações e animais de criação, demonstrando que houve forte sofrimento emocional e físico das pessoas.

Com esta situação conflituosa e um novo cenário jurídico se apresentando, pode-se dizer que passaram por um processo de mudança e de percepção sobre si mesmo, revelando e assumindo uma identidade quilombola que, como toda identidade, é uma construção e é também relacional, porque demarcamos quem é de dentro e faz parte do grupo/da comunidade e quem é de fora do grupo/comunidade, constituindo "[...] um espaço social marcado pela terra e pelo parentesco considerando a co-participação [sic] em valores e práticas culturais próprias e especificamente através da construção de formas de organização baseadas em solidariedade e reciprocidade." (GUSMÃO, 1992, p. 117).

Acrescentando mais um elemento nesta reflexão inicial sobre identidade, há também uma questão de poder e de política, pois depende de um processo de identificação, de diferenciação e de separação das pessoas que vivem nas comunidades. Essas ações não são práticas neutras, elas estão permeadas o tempo todo por conflito e negociação. A identidade parte do pressuposto de que é construída dentro do grupo social, cada grupo demonstrará quais são seus elementos de particularidade que os distinguirá dos outros grupos, mas em suas lutas políticas, muitas vezes se reúnem para obter forças e expressão nesse mundo globalizado.

Na era da globalização, faz-se presente a defesa de certos direitos sociais, culturais e políticos advindos das demandas específicas dos grupos minoritários como é o caso dos quilombolas, dos grupos indígenas, das comunidades tradicionais na sua concepção mais ampla e podemos inseri-los na categoria de movimentos sociais minoritários e nos "novos territórios da diversidade." (CAVALCANTI, 2013, p. 71).

Hoje as comunidades remanescentes de quilombo lutam pelo reconhecimento da sua autodeclaração de portadoras de direitos, conforme o que determina a Constituição de 1988 e a legislação em vigor, como os decretos: Decreto n. ${ }^{\circ}$ 4.883, de 20 de novembro de 2003; Decreto n. $^{\circ} 4.887$, de 20 de novembro de 2003; o Decreto Legislativo n. ${ }^{\circ} 143$ (do Congresso Nacional, em 20 de junho de 2002) promulgado pelo Decreto n. ${ }^{\circ} 5.051$, de 19 de abril de 2004 e a Instrução Normativa n. $^{\circ} 57$ de $2^{\circ}$ de outubro de 2009 do INCRA, entre outros.

As dificuldades que as comunidades remanescentes de quilombo têm em obter os títulos de suas terras advêm do Estado brasileiro que, com frequência, é moroso e não tem compromisso em regularizar as titulações, porque isso significaria, muitas vezes, desapropriar fazendas para atribuir títulos coletivos de terra para grupos considerados minoritários, por isso, que a luta é contínua tanto ao acesso quanto a titulação de seus territórios, isto é, a terra e todos os elementos que fazem parte de suas vidas dentro do seu território.

\section{CONSIDERAÇÕES FINAIS}

Os grupos sociais assumiram suas identidades para atender as questões jurídicas, políticas, sociais e culturais, as comunidades negras rurais descendentes dos antigos quilombos ou dos antigos grupos de camponeses negros (SCHMITT; TURATTI; CARVALHO, 2002), que têm uma profunda relação com o território, mas que não estavam conseguindo obter seus direitos territoriais, Fiabani (2012, p. 317) afirma que "[...] o fato de que, a partir de 1988, multiplicaram-se as comunidades remanescentes não significa que todas são oriundas de quilombo [históricos]. Em realidade [...] escancarou-se o problema fundiário brasileiro no que se refere às comunidades rurais afrodescendentes", e, através da autoidentificação e da legislação vigente, as comunidades remanescentes de quilombo viram a possibilidade para a titulação de suas terras e acesso aos direitos à saúde, à educação e à 
moradia, ressalto que o conceito histórico de quilombo foi ressignificado com a Constituição Cidadã de 1988.

Giddens argumenta que "a vida é marcada por um lugar" e que envolve elementos econômicos, produtivos, políticos, culturais e sociais. O lugar tem sua importância porque entre várias as perspectivas, uma delas trata das "relações localizadas [...] em que o lugar ainda não foi transformado pelas relações tempo-espaço distanciadas [...] o meio local é o lugar de feixes de relações sociais entrelaçadas, cuja pequena extensão espacial garante sua solidez no tempo" (GIDDENS, 1991, p. 93).

Neste sentido, as comunidades remanescentes de quilombo têm ligações com o lugar, com a terra, com o rio, com o cerrado, com a floresta, com as veredas, isto é, o modo de vida destas comunidades está ligado ao meio ambiente (ao bioma) em que vivem. A sabedoria em usar determinadas plantas que são consideradas medicinais no tratamento de doenças; saber o tempo de plantar e colher; o período das festas, danças, orações, entre outros saberes, assim, as aproximadamente três mil comunidades remanescentes de quilombos espalhadas pelo país demonstram a forma como foram se apropriando dos lugares ao longo do tempo.

\section{REFERÊNCIAS}

ALMEIDA, Alfredo W. B. de. "Terras de Preto, Terras de Santo, Terras de Índio: uso comum e conflito. In: Diversidade do Campesinato: expressões e categorias. Estratégias de reprodução Social - v.2. Organização Emília P. Godoi; Marilda A. Menezes; Rosa Azevedo Marin. São Paulo: Editora da UNESP; Brasília: NEAD, 2009. p. 39-66.

ALMEIDA, Alfredo W. B. de. Quilombos e as Novas Etnias. Manaus: UEA Edições, 2011.

APA-TO. Os Territórios Quilombolas no Tocantins. Tocantins: APA-TO, 2012.

ARRUTI, José Maurício. Comunidades Negras Rurais: entre a memória e o desejo. Suplemento Especial de Tempo e Presença, ano 20, n. 298, p. 15-18, mar./abr. 1998.

ARRUTI, José Maurício. As comunidades negras rurais e suas terras: a disputa em torno de conceitos e números. Dimensões: Revista em História da UFES, Vitória, v. 14, p. 243-269, 2002.

ARRUTI, José Maurício. Quilombos. In: Raça: novas perspectivas antropológicas. Organização Osmundo Pinho; Livio Sansone. 2.ed. rev. Salvador: EDUFBA/ABA, 2008. p. 315-350.

BRASIL. Constituição da República Federativa do Brasil. Brasília, DF: Senado Federal: Centro Gráfico, 1988.

BRASIL. IBGE. Estado do Tocantins. Rio de Janeiro, 2020. Disponível em: http://www.ibge.gov.br/Estadosat/perfil.php?sigla=to. Acesso em: 09 abr. 2020.

BUAINAIN, A. M.; GARCIA, J. R.; VIEIRA FILHO, J. E. R. A economia agropecuária do Matopiba. Revista Estudos Sociedade e Agricultura, v. 26, n. 2, p. 376-401, jun./set. 2018.

\footnotetext{
${ }^{6}$ Para Giddens "Lugar é melhor conceitualizado por meio da ideia de localidade, que se refere ao cenário físico da atividade social como situado geograficamente. " (1991, p. 22) e na divisão que faz entre culturas prémodernas e modernas diz que "A comunidade local [é] como um lugar, fornecendo um meio familiar." (1991, p. 92).
} 
CARDOSO, Ciro Flamarion S. A brecha camponesa no sistema escravista. In: Agricultura, escravidão e capitalismo. Petrópolis, Rio de Janeiro: Vozes, 1979. p. 133-154.

CARDOSO, Ciro Flamarion S. Escravo ou Camponês? O protocampesinato negro nas Américas. São Paulo: Brasiliense, 2004.

CARVALHO, João Carlos. M. de. Camponeses no Brasil. Petrópolis/RJ: Vozes, 1978.

CAVALCANTI, J. S. B. "Comunidades rurais e os desafios da sociedade contemporânea". In: Mundo rural: mito ou realidade? Vanda A. Silva; Renato M. Carmo. São Paulo: Annablume, 2013. p. 67-82.

CHAGAS, Miriam de Fátima. "A política do reconhecimento dos 'remanescentes das comunidades dos quilombos" In: Horizontes Antropológicos: Sincretismo afro-brasileiro e resistência cultural. Porto Alegre, ano 7, n. 15, p. 209-235, julho/2001.

FIABANI, Adelmir. Mato, palhoça e pilão: o quilombo, da escravidão às comunidades remanescentes [1532-2004]. 2. ed. São Paulo: Expressão Popular, 2012.

FIABANI, Adelmir. O quilombo antigo e o quilombo contemporâneo: verdades e construções. In: SIMPÓSIO NACIONAL DE HISTÓRIA, 24. 2007, São Leopoldo, RS. Anais[...]. São Leopoldo, RS: UNISINOS, 2007.

GUANZIROLI, Carlos E. Agronegócio no Brasil: perspectivas e limitações. EconomiaTextos para discussão, n. ${ }^{\circ}$ 186. Universidade Federal Fluminense, Faculdade de Economia, abril/2006.

GUIDDENS, Anthony. As Consequências da Modernidade. $5^{\text {a }}$ reimpressão. São Paulo: Ed.UNESP, 1991.

GUSMÃO, Neusa Maia Mendes. Negro e Camponês: política e identidade no meio rural brasileiro. São Paulo em Perspectiva, v. 6, n. 3, p. 116-122, jul./set., 1992.

JORGE, Amanda Lacerda. O processo de construção da questão quilombola: discursos em disputa. Rio de Janeiro: Gramma, 2016.

KARASCH, Mary. Os quilombos do ouro na Capitania de Goiás. In: Liberdade por um fio: história dos quilombos no Brasil. Organização J. J. Reis; F. dos S. Gomes. São Paulo: Cia das Letras, 1996. p. 240-262.

LOPES, Nei. História e Cultura Africana e Afro-brasileira. SP: Barsa Planeta, 2008.

LOPES, Rita de Cássia Domingues. Identidade e territorialidade na Comunidade Remanescente de Quilombo Ilha de São Vicente na região do Bico do PapagaioTocantins. 2019. 301f. Tese (Doutorado em Antropologia) - Programa de Pós-Graduação em Antropologia. UFPE, CFCH. Recife, 2019.

MAESTRI, Mário. A aldeia ausente: índios, caboclos, cativos, moradores e imigrantes na formação da classe camponesa no Brasil. In: A Questão Agrária no Brasil. Organização João Pedro Stedile. São Paulo: Expressão Popular, 2005a. V.2. p. 217-277. 
MAESTRI, Mário. Terra e Liberdade: as comunidades autônomas de trabalhadores escravizados no Brasil. In: Afrobrasileiros: História e Realidade. Organização Luiz C. Amaro; Mario Maestri. Porto Alegre: EST Edições, 2005b. p. 85-113.

MARQUES, Marta Inez Medeiros. A atualidade do uso do conceito de camponês. Revista NERA, Núcleo de Estudos, Pesquisas e Projetos de Reforma Agrária - UNESP, Presidente Prudente, ano 11, n. 12, p. 57-67, jan./jun. 2008.

MIRANDA, Evaristo de. Matopiba: caracterização, agendas e agência. GITE/EMBRAPA, 2015.

MOURA, Clóvis. Os Quilombos e a Rebelião Negra. São Paulo: Brasiliense, 1981.

MOURA, Glória. Festa dos quilombos. Brasília, DF: Ed. UNB, 2012.

NASCIMENTO, Júnior Batista do. Tocantins: História e Geografia. Revisada, ampliada e atualizada. $6^{\circ}$ ed. Palmas: s/ed, 2009.

O’DWYER, Eliane C. Introdução: Os quilombos e a prática profissional dos antropólogos. In: O'DWYER, E. C. (Org.). Quilombos: identidade étnica e territorialidade. Rio de Janeiro: Ed.FGV, 2002. p. 13-42.

RATTS, Alex. (Re) conhecer quilombos no território brasileiro: estudos e mobilizações. In: Brasil afro-brasileiro. Organização Maria Nazareth S. Fonseca. Belo Horizonte: Autêntica, 2000. p. 307-326.

RATTS, Alex. Traços étnicos: espacialidades e culturas negras e indígenas. Fortaleza: Museu do Ceará; Secult, 2009.

REESINK, Edwin. Substantial Identities in "Rural Black Communities" in Brazil: a Short Appraisal of Some Community Studies. Vibrant - Virtual Brazilian Anthropology, Brasília, ABA, v. 5, n.1, jan./jun., 2008.

SCHMITT, A.; TURATTI, Maria Cecília M.; CARVALHO, Maria Celina P. A atualização do conceito de Quilombo: Identidade e Território nas definições teóricas. Ambiente \& Sociedade, Campinas, ano V, n. 10, jan./jun. 2002.

SHANIN, Teodor. "A Definição de Camponês: Conceituações e Desconceituações - o velho e o novo em uma discussão marxista". Estudos CEBRAP 26, março/1990, p. 42-80.

SILVA FILHO, Geraldo. Tênues fronteiras: escravidão, economia e sociedade no Tocantins Colonial. In: Ensaios de Geografia e História do Tocantins para uma interpretação crítica. Organização G. Silva Filho; R. S. Santos. Palmas: Nagô, 2012, p. 78-93. 